\title{
WATER BUDGETS OF CAVE CRICKETS, HADENOECUS SUBTERRANEUS AND CAMEL CRICKETS, CEUTHOPHILUS STYGIUS
}

\author{
Eugene H. Studier, Wit.tiam D. Wares II, Kathifen H. Lavoie and Julie A. M. Linn* \\ Department of Biology, University of Michigan-Flint, Flint, Michigan 48502-2186, USA
}

(Reccived 29 April 1986)

\begin{abstract}
Studies of cave and camel crickets from cave entrances in Mammoth Cave National Park have produced estimates of total water budgets and component contributions to water balance.

2. Weight specific ( $\mathrm{mg} / \mathrm{g}$ crop-free live weight/hr) total water loss $(3.200 \mathrm{vs} 2.220)$ and water gained in food (2.393 vs 1.902$)$ are greater in cave than in camel crickets, respectively.

3. Weight specific evaporative water loss in both humid, still air (2.269 vs 1.325$)$ and dry, moving air (15.28 vs 9.85 ) is greater in cave than in camel crickets, respectively.
\end{abstract}

\section{INTRODUCTION}

Vandel (1965) stated that the level of humidity is the most important environmental factor in the life of terrestrial cavernicoles and credited Bedel and Simon (1875) with first recognizing this factor. Data supporting this generalization among cavernicolous arthropods derive primarily from behavioral microhabitat selection studies (Mitchell, 1971; Edwards, 1971; Bull and Mitchell, 1972; and, Lucarelli and Sbordoni, 1977) and studies of dehydration tolerance (Mitchell, 1971; Bull and Mitchell, 1972: Wilson, 1975). These studies suggest that cave insects tend to select microhabitats that are cool with high relative humidity. Physiologic studies of water relations in cavernicolous arthropods have dealt mostly with measures of evaporative water loss (Herreid, 1969; Vannier, 1977). Hadley et al. (1981), compared several measures of water and metabolic relationships between an epigean and a cave spider. Water loss rates were shown to correspond to the environmental stresses each species encountered in their normal habitat. The only aspect of water budgets that has been quantified for cave-dwelling crickets is transpiratory water losses in several Australian species (Campbell, 1980).

This study presents data on all aspects of the water budgets of two cavernicolous crickets and continues our studies of the physiological ecology of these insects (Studier et al., 1986a,b).

\section{MATERIALS AND METHODS}

Studies on cave crickets, Hadenoecus subterraneus, were conducted during the last week of April and first week of May, 1985, in Floyd Collins Crystal Cave and White Cave in Mammoth Cave National Park ((MCNP), Ky. Data on camel crickets, Ceuthophilus stygius, were collected primarily during the last week of June, 1985, in Great Onyx Cave, MCNP, Ky. Studies of evaporative water loss (EWL) in dry

*Present address: Department of Hcalth Bchavior/ Education, School of Public Health, University of Michigan, Ann Arbor, MI 48109, USA. air were performed on both species at the caves indicated above in October, 1985. All $H$. subterraneus studied were adults and the $C$. stygius were adults or penultimate instars (T. H. Hubbell, personal communication).

Data on total water loss, water lost in wastes, water gained in food and metabolic water production were derived from the long term weight loss studies previously described (Studier et al., 1986a). Total water loss was estimated by mean long term total body weight loss minus rate of dry waste lost. Water lost in wastes was calculated from rate of dry wastes produced assuming those wastes had the same fractional water content as cricket carcasses. EWL is estimated as total water loss minus water loss in wastes. Water gained in food was determined from rate of wet crop content disappearance adjusted by fractional water level of crop contents. Metabolic water production was converted from estimated metabolic rate assuming aerobic glycolysis.

Rate of EWL in humid air was determined for $H$. subterraneus on 30 May 1985 in Floyd Collins Crystal Cave. Saturated solutions of specific salts (Winston and Bates, 1960) were poured into the bottom part of plastic "pie savers" $(8 \mathrm{~cm}$ high $\times 30 \mathrm{~cm}$ diameter $)$ lined with a tightfitting, lipped, shallow ( $4 \mathrm{~cm}$ high) plastic liner. A circle of screen cloth ( $1 / 4$ in. mesh) rested on the lip of the liner above the solution. This apparatus was placed inside plastic garbage bags which were sealed leaving ample head room above the screening. When checked in the cave setting (Certified Hygrometer and Temperature Indicator, Model HTAB-176, Abbeon Cal, Inc., Santa Barbara, Calif.), these devices reached constant relative humidities within $1 \mathrm{hr}$. Containers maintained relative humidities of $71,84.5,93.9$, 98.5 , and $100 \%$. Six crickets (three females/three males) placed in cylindrical cages $(4 \mathrm{~cm}$ diameter $\times 15 \mathrm{~cm}$ length) constructed of plastic screen cloth (1/16 in mesh), and a control (empty) cage were weighed and placed into the containers described above. After a 7-hr mid-day exposure, at a cave temperature of $13.5^{\circ} \mathrm{C}$, caged crickets and the control cage were reweighed to the nearest $\mathrm{mg}$ (Ohaus Centogram Balance, Union, N.J.). For those crickets which did not defecate while caged, weight loss is an estimate of EWL.

Determination of EWL in dry, moving air for both species in the previously mentioned caves was carried out in October, 1985. Materials were allowed to equilibrate with the cave environment $\left(100 \% \mathrm{RH}, 13.6^{\circ} \mathrm{C}\right.$ in Crystal Cave, $100 \% \mathrm{RH}, 14.0^{\circ} \mathrm{C}$ in Great Onyx). Compressed air, dried by flowing through silica gel, was passed at constant flow-rate $(150 \mathrm{cc} / \mathrm{min})$ over individual adult crickets of both sexes in 
a large (35 mm diameter $\times 190 \mathrm{~mm}$ length) test tube. Plastic screen cloth (1/16-in. mesh) lining the interior of the test tube provided secure footing for crickets. Outflow air was directed through a flow-meter (Matheson, Model No. 62 2SV) for $25 \mathrm{~min}$ to ensure that any condensed water had evaporated and that chamber air approximated to $0 \%$ relative humidity. Outflow air was then redirected through a pre-weighted (Fisher Scientific Electronic Analytical Balance, Model 2100) column of silica gel for $1 \mathrm{hr}$. Weight gain by the silica gel represents EWL after correction for any weight changes in the control system which was treated exactly as experimental except that no cricket was contained in the chamber.

Crickets from EWL in dry air studies were sacrificed in chloroform vapor and stored individually in test tubes at $4 \mathrm{C}$ for one week. Length and diameter measurements (accuracy to $0.001 \mathrm{in}$.) were taken with a caliper (Fowler Max-Cal Caliper No. 54-200-000, Fowler, Inc. Newton. MA). Surface area was calculated for each body segment as if they were cylindrical. Length was taken only on the longest axis of the body segment. Diameter was an average of between two and six measurements taken in various planes of each segment. Measurements were taken to include an equal number of large diameter and small diameter areas. Body segments used in surface area determinations were separated from the thorax/abdomen prior to measurement and included antennae, head, large labial and labral palps, all legs, thorax/abdomen, hind cerci and ovipositors. Total surface area was determined as the sum of the parts. Total surface area in in. ${ }^{2}$ was then converted to $\mathrm{mm}^{2}$.

\section{RESULTS}

Component and total water budgets of cave and camel crickets in still, humid air are given in Table 1.
The only gender related differences are that crop-free live weight (CFLW) and total body water (TBW) of camel cricket males are greater than in females $(t=3.34 ; \quad$ d.f. $=14 ; \quad P<0.01 ; \quad$ and $t=3.997$; d.f. $=14 ; P<0.01)$. Since CFLW and TBW of cave crickets of both sexes $(411 \pm 17 \mathrm{mg}, N=13$ and $300.1 \pm 11.9, N=13$ ) is significantly less than CFLW and TBW of female camel crickets $(t=12.08$; d.f. $=18 ; \quad P<0.001 ; \quad$ and $t=28.76 ; \quad$ d.f. $=18$; $P<0.001$, respectively), crop-empty camel crickets have greater biomass than cave crickets. Regarding weight specific comparisons ( $\mathrm{mg} / \mathrm{g} \mathrm{CFLW/hr}$ ) of water balance components between species, cave crickets gain water from food more rapidly than camel crickets $(2.393 \pm 0.138, N=12$ vs $1.902 \pm$ $0.187, \quad N=16 ;$ respectively, $t=2.11 ; \quad$ d.f. $=26$; $P<0.05)$. Total water loss in $H$. subterraneus $(3.200 \pm 0.148 ; N=12)$ is greater than in $C$. stygius $(2.220 \pm 0.069, \quad N=16 ; \quad t=5.99, \quad$ d.f. $=26 ; \quad P<$ $0.001)$; and, EWL of cave crickets $(2.269 \pm 0.226$; $N=12)$ is more rapid than in camel crickets $(1.325 \pm 0.172 ; t=3.33$, d.f. $=26 ; P<0.01)$.

The short term weight loss study in still air of varying water content shows a significant relation between relative humidity deficit $(\mathrm{RHD}=100$-test relative humidity) and EWL $(F=3.28$; d.f. $=3$ and $19 ; P<0.05)$. The least squares regression analysis gives the equation:

$$
\mathrm{EWL}(\mathrm{mg} / \mathrm{hr})=0.116 \mathrm{RHD}(\%)+1.26 \text {. }
$$

Since these studies were carried out at constant temperature, RHD can be converted to water vapor

Table 1. Water balance components of male (M) and female (F) cave crickets, Hadenoecus subterraneus, and camel crickets, Ceuthophilus stygius, estimated from long term weight loss in humid, still air. Crop free live weight (CFLW) and total body water (TBW) are in grams. All other values are in $\mathrm{mg} / \mathrm{g}$ CFLW per hr. Entries include arithmetic mean and standard error of the mean in parentheses

\begin{tabular}{|c|c|c|c|c|}
\hline \multirow[b]{2}{*}{ Parameter } & \multicolumn{2}{|c|}{ H. subterraneus } & \multicolumn{2}{|c|}{ C. stygius } \\
\hline & $F ; n=7$ & $M ; n=5$ & $F ; n=8$ & $M ; n=8$ \\
\hline \multirow[t]{2}{*}{ CFLW } & 0.426 & 0.390 & 1.055 & 1.304 \\
\hline & $(0.012)$ & $(0.037)$ & $(0.051)$ & $(0.055)$ \\
\hline \multirow[t]{2}{*}{ Total loss } & 3.381 & 2.946 & 2.239 & 2.201 \\
\hline & $(0.135)$ & $(0.282)$ & $(0.076)$ & $(0.121)$ \\
\hline \multirow[t]{2}{*}{ Waste loss } & 0.955 & 0.898 & 1.041 & 0.750 \\
\hline & $(0.194)$ & $(0.177)$ & $(0.734)$ & $(0.277)$ \\
\hline \multirow[t]{2}{*}{ EWL } & 2.492 & 2.074 & 1.250 & 1.451 \\
\hline & $(0.314)$ & $(0.343)$ & $(0.207)$ & $(0.285)$ \\
\hline \multirow[t]{2}{*}{ Food gain } & 2.528 & 2.202 & 1.896 & 1.753 \\
\hline & $(0.736)$ & $(0.268)$ & $(0.199)$ & $(0.316)$ \\
\hline \multirow[t]{2}{*}{ Metabolic gain } & 0.408 & 0.451 & 0.419 & 0.423 \\
\hline & $(0.045)$ & $(0.093)$ & $(0.079)$ & $(0.077)$ \\
\hline \multirow[t]{2}{*}{ TBW! } & 0.302 & 0.298 & 0.752 & 0.920 \\
\hline & $(0.008)$ & $(0.030)$ & $(0.010)$ & $(0.040)$ \\
\hline
\end{tabular}


Table 2. Body parameters and evaporative water loss (EWL) in dry, moving air in cave and camel crickets. Cave crickets were tested at $13.6^{\circ} \mathrm{C}$ at a water vapor pressure deficit of $11.68 \mathrm{~mm} \mathrm{Hg}$ and camel crickets at $14 \mathrm{C}$ with a deficit of $11.99 \mathrm{mmHg}$. Asterisks indicate level of significance of $t$-tests with ${ }^{*}=P<0.05$, ${ }^{* *}=P<0.01$ and ${ }^{* * *}=P<0.001$. Sample size for each sex of each species is 8 . HFL $=$ hind femur length; CFLW $=$ crop free live weight

\begin{tabular}{|c|c|c|c|c|c|c|}
\hline \multirow[t]{2}{*}{ Parameter } & \multicolumn{3}{|c|}{$\underline{H}$. subterraneus } & \multicolumn{3}{|c|}{ C. stygius } \\
\hline & $F$ & $M$ & $t$ & $\mathrm{~F}$ & $M$ & $t$ \\
\hline \multirow[t]{2}{*}{ EWL $(\mathrm{mg} / \mathrm{hr})$} & 13.24 & 6.46 & $2.27^{\star}$ & 16.29 & 14.26 & NS \\
\hline & $(2.88)$ & $(0.80)$ & & $(1.60)$ & $(1.58)$ & \\
\hline \multirow[t]{2}{*}{$\mathrm{HFL} \quad(\mathrm{mm})$} & 22.2 & 20.6 & $6.40^{\star \star \star}$ & 22.4 & 21.2 & NS \\
\hline & $(0.2)$ & $(0.2)$ & & $(0.5)$ & $(0.7)$ & \\
\hline \multirow[t]{2}{*}{ Tot $w t(\mathrm{mg})$} & 642.2 & 625.6 & NS & 1890.2 & 1301.9 & $3.83^{* *}$ \\
\hline & $(38.4)$ & $(49.7)$ & & $(118.4)$ & & \\
\hline \multirow[t]{2}{*}{$\operatorname{CFLW}(\mathrm{mg})$} & 491.9 & 391.3 & $6.34 * \star \star$ & 1216.9 & 1267.0 & NS \\
\hline & $(11.9)$ & $(10.4)$ & & $(48.3)$ & $(76.5)$ & \\
\hline \multirow[t]{2}{*}{$S \cdot A \cdot\left(m^{2}\right)$} & 1387.7 & 244. & $2.63^{\star}$ & 2293. & 1881 & 3.27 ** \\
\hline & $(26)$. & $(47)$. & & $(84)$. & $(94)$. & \\
\hline
\end{tabular}

pressure deficit or saturation deficit and the intercept of the equation estimates EWL under water saturated conditions found in these biologically active caves.

Reduced data for EWL in dry, moving air are given in Table 2. CFLW is less than total weight in male $(t=4.61 ; P<0.001)$ and female $(t=3.74$, $P<0.01)$ cave crickets as well as female $(t=5.26$; $P<0.001)$ camel crickets. Comparisons between species show camel crickets to have significantly greater EWL than cave crickets $(15.28 \pm 1.12$ vs $9.85 \pm 1.69 \mathrm{mg} / \mathrm{hr}$, respectively; $t=3.43 ;$ d.f. $=30$; $P<0.01)$, significantly greater total weights than cave crickets $(1596.1 \pm 106.2$ vs $633.8 \pm 30.4 \mathrm{mg}$, respectively; $t=8.71 ; \quad$ d.f. $=30 ; \quad P<0.001$ ); significantly greater CFLW than cave crickets $(1242.0 \pm 44.0$ vs $441.6 \pm 15.1 \mathrm{mg}$, respectively; $t=17.2 ; \quad$ d.f. $=30 ; \quad P<0.001) ; \quad$ and significantly greater surface areas $\left(2086 \pm 81\right.$ vs $1316 \pm 32 \mathrm{~mm}^{2}$, respectively; $t=8.841$; d.f. $=30 ; P<0.001)$.

\section{DISCUSSION}

Data derived from the long term weight loss experiment represent the most complete estimates of total water budgets and component contribution to water economy of the crickets studied. These studies also have the greatest biological applicability since they were done in caves under natural conditions. With regard to all estimates derived for $H$. subterraneus it is important to note that the percentage of body water did not change throughout the 5-day experimental period and weight loss during that experimental period was linear (Studier et al; 1986a). These data indicate that cave crickets maintained overall water balance and that components of water economy were constant throughout the period of observation. For camel crickets, however, the percentage of body water of female crickets decreased significantly $(t=6.56$; d.f. $=14 ; P<0.001)$ over the period of observation and weight loss is curvilinear throughout that same period (Studier et al., 1986b) which suggest that female $C$. stygius were in negative water balance during the study. Furthermore, since average values were used to calculate total water budgets and component contributions for $C$. stygius, values shown in Table 1 underestimate levels during the first 2 days of observation and overestimate those same parameters during the last 2 days of the study period

Weight specific rate of total water turnover (= total loss) of $H$. subterraneus was significantly greater than for $C$. stygius (Table 1). These differences relate to the higher surface area to mass ratio of cave crickets compared to camel crickets (Table 2). This greater observed relative water loss in cave crickets was expected in view of the different roosting habits of the two species. Cave crickets roost individually or in loose groups in deeper cave regions where ambient humidity is higher and more constant than those areas at the cave entrance occupied by camel crickets. Camel crickets often roost in tight clusters or wedged individually in tight cracks in the ceiling. Additionally, the cuticle of cave crickets seems to be thinner, more elastic and appears to be a less effective barrier to water flux than that of camel crickets. Camel crickets are very shiny compared to cave crickets, suggesting the presence of more epicuticular lipids. Camel crickets also routinely forage outside caves more frequently than cave crickets (Campbell, 1976; Leja and Poulson, 1984). Our October observation that male $C$. stygius had empty crops while females didn't (i.e. total weight of males was not significantly different than CFLW, Table 2) is interesting in view of the routine nightly exodus of 


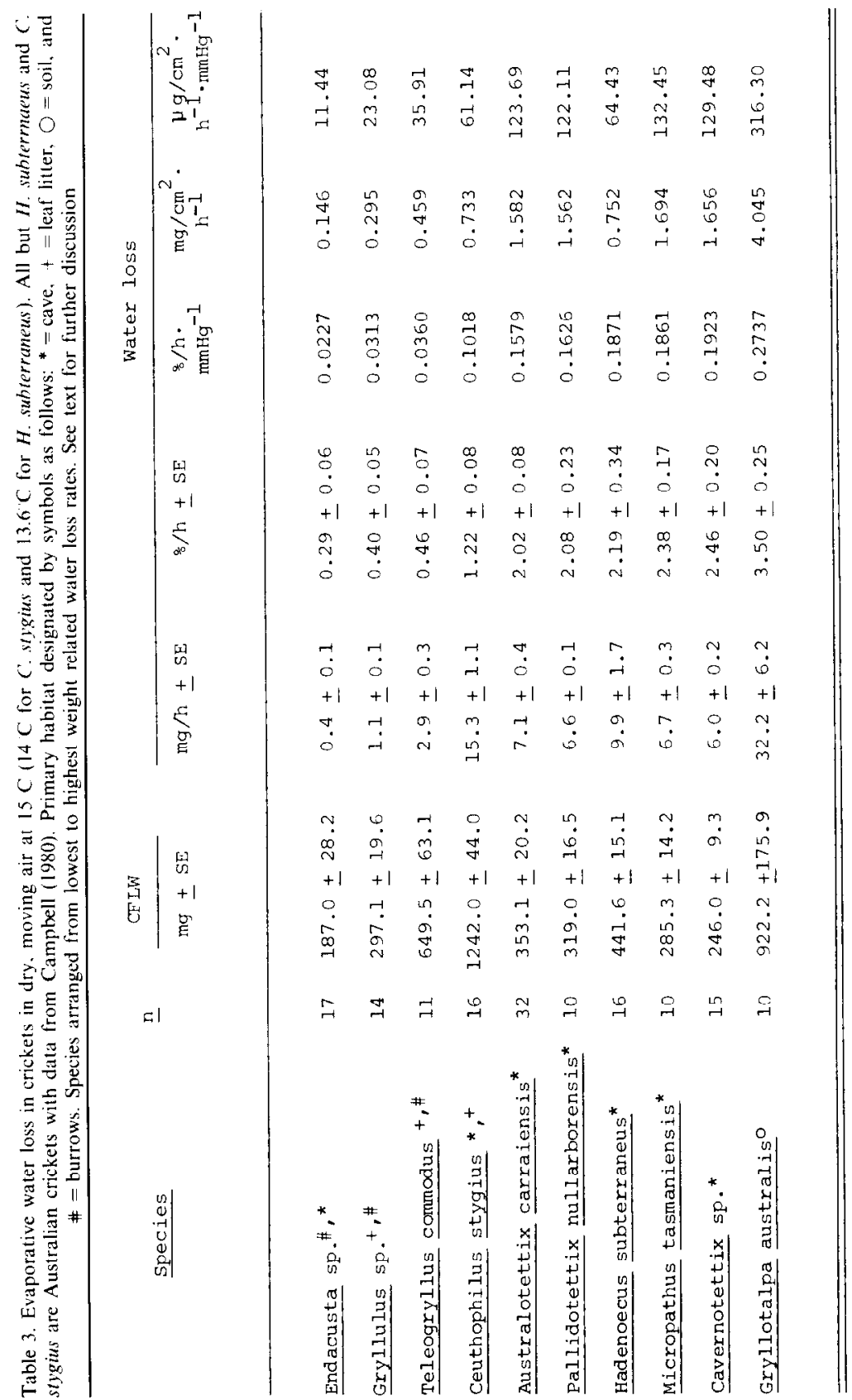


this species. Empty crops in males indicate lack of feeding exodus for several days (Studier et al., 1986b). Many camel crickets were observed in copulo in October and the active breeding period in C. stygius appears to be much more time restricted than in $H$. subterraneus due to the more seasonal appearance of adults. Male $C$. stygius behavior of remaining in the cavern entrance rather than emerging to feed may increase the likelihood of successful copulation with females as they return from foraging bouts.

We have been unable to locate any literature values for arthropods for comparison purposes where total water loss includes more than EWL. Sufficient data in a variety of mammals have been accumulated to yield an allometric equation relating total water loss to body mass (Altman and Dittmer, 1968). Estimated total water loss projected for mammals the size of cave and camel crickets would be 209.9 and $243.4 \mathrm{mg} / \mathrm{g}$ live weight per $\mathrm{hr}$, respectively. These are two orders of magnitute greater than values found in crickets (Table 1).

In view of the very low metabolic rates of $H$. subterraneus and $C$. stygius in comparison to expected values of insects for their size (Studier et al., $1986 a, b)$, metabolic water production in these trogloxenic insects may prove to be a lesser source of water gain than in epigean species.

There are marked differences in the contributions of water balance components to the total water budgets in the two species. In cave crickets, EWL is $72.1 \%$ of tolal losses while EWL represents only $60.9 \%$ of total losses in camel crickets. Water lost in wastes contributes 29.4 and $40.3 \%$, respectively, to total losses. The significantly greater water gain from food by cave crickets can probably be attributed to the fact that full cave crickets contain a greater mass of crop contents than camel crickets (Studier et al., $1986 a, b)$

Wharton (1985), in his recent review of water balance in insects, discussed weight loss over time experiments including advantages and disadvantages of utilizing a single group of animals weighed successively as opposed to randomly selected animals exposed for each time period of interest. In that review, Wharton also points out that such weight loss experiments are characteristically performed on experimental animals which are standardized in such a manner that they do not eat, excrete, secrete, grow, or reproduce during periods of exposure to test conditions of controlled ambient temperature and (usually $0 \%$ ) relative humidity. Although not included in Wharton's standardization list, tested insects are also allowed very limited mobility. Such studies provide a large literature allowing comparison of only EWL in many insects and measure an extreme physiological response to dehydrating conditions which have little direct biological applicability to water balance under natural or quasi-natural conditions.

We have determined EWL for both cricket species in the natural, wet, still air environment existing in caves (Table 1) as well as in moving, dry air conditions (Table 2). EWL was also studied in $H$. subter raneus at a range of high, controlled humidities in still air during the short term weight loss study. Results of an ANOVA of weight loss as a function of exposure relative humidity show that a significant inverse relationship exists. Weight changes of caged crickets during this short term ( $7 \mathrm{hr}$ ) study, however, were quite small and highly variable suggesting this protocol to be of severely limited experimental value. Since the $95 \%$ confidence interval for the slope of the least squares regression line includes zero, the regression equation given in the results section is quite tenuous and of highly questionable predictive value. It may well be fortuitous that projected EWL in water saturated air $(1.26 \mathrm{mg} / \mathrm{hr})$ agrees well with EWL determined from the long term weight loss studies $(0.81-1.06 \mathrm{mg} / \mathrm{hr}$; Table 1$)$, and calculated EWL in dry air $(12.9 \mathrm{mg} / \mathrm{hr})$ agrees with values found in moving, dry air (6.5-13.2 $\mathrm{mg} / \mathrm{hr}$; Table 2).

The only available comparative data on EWL in humid air appears to be that reported by Campbell (1980) for Australotettix carraiensis, an Australian cave-dwelling cricket. He reported a value of $0.28 \pm 0.03 \% / \mathrm{hr}$ for those crickets in moving air at $98 \%$ relative humidity at $15 \mathrm{C}$. Values for cave crickets $(0.35$ and $0.27 \% / \mathrm{hr}$ for females and males, respectively) and camel crickets $(0.18$ and $0.21 \% / \mathrm{hr}$ for females and males) calculated from the long term weight loss experiment (Table 1) agree closely with Campbell's data. Weight specific EWL of camel crickets in humid air is, however, markedly less than in the other crickets.

Although many references on evaporative (transpiratory) water loss in arthropods exposed to dry air are available (Wigglesworth, 1945; Holdgate, 1956; Mead-Briggs, 1956; Edney, 1971; Vanier, 1977; Arlian and Veselica, 1979: and many others), it seems most reasonable to compare values for cave and camel crickets with other related orthopterans as shown in Table 3. With the exception of values based on surface area, EWL of $H$. subterraneus lie in the middle of the range of EWL values for the four strictly cave-dwelling Australian species while EWL of $C$. stygius, as $\% / \mathrm{hr}$, are less than $A$. carraiensis $(t=7.07$, d.f. $=46 ; P<0.001)$ but more than Teleo gryllus commodus $(t=7.15$, d.f. $=25, P<0.001)$. The mole cricket (Gryllotalpa australis) exhibits remarkably high EWL in dry air and would appear to be more susceptible to dehydration than the strictly cave-dwelling crickets which, in turn, lose transpiratory water more rapidly than leaf-litter or burrow utilizing crickets.

While weight specific EWL of $H$. subterraneus and C. stygius fall nicely into expected levels, area specific EWL values are much lower than expected. Considerable discussion of the problems associated with determination of surface area of insects is available (see Wharton, 1985). Using a method different from ours, Campbell (1980) established a relationship between body mass and surface area for two Australian cricket species (Endacusta sp, and Australotettix carraiensis) which are morphologically similar to $H$. subterraneus and C. stygius, respectively. Based on his equations, the surface area of $H$. subterraneus would range from 503 to $516 \mathrm{~mm}^{2}$ and $C$. stygius from 926 to $1043 \mathrm{~mm}^{2}$. Use of those calculated surface areas would bring surface area specific EWL parameters for $H$. subterraneus and $C$. stygius in close agreement with Campbell's data. Part of the reason that values projected from his equations are much lower than our 
measured values is Campbell's lack of inclusion of antennal and palp surface area in total surface area, however, there appears to be extreme variation in estimates of suface area within and between techniques used. Area specific EWL estimates are, therefore, much more variable and less reliable for comparison than weight specific EWL. It should be mentioned, however, that crop-empty body mass should be used since gut contents may weigh as much as the gut-empty body (Wightman, 1981; Studier et al., 1986a).

In summary, rates of water gain and loss in $H$. subterraneus are significantly greater than in $C$. sty gius due primarily to a greater rate of water gain in food and loss as EWL, respectively. These observations correlate to differing behavior patterns in roosting and foraging seen in the two species. $H$. subterraneus roosts in the constant water saturated or near-saturated conditions deeper in caves and forages sporadically outside caves only when low saturation deficits exist. $C$. stygius is able to roost in the more variable (in terms of relative humidity and temperature) conditions at cave entrances and can forage outside the cave refuge under a wider range of environmental conditions.

Acknowledgements-We would like to thank the many people who gave generously of their time, effort, and ideas during the field work, especially Ann Studier, Terry Bellis, Ernie Szuch, and Ann Szuch. Ellen Levy offered insights into cave cricket biology. Dr Tom Poulson, Dr Mike Martin, Dr T. H. Hubbell and Mike Kauffman read drafts of the manuscript and offered useful comments. We thank Dr Hubbell for verifying the species indentification and for aging the crickets. We would like to thank the National Park Service and its personnel for providing access to the cave, and to the Cave Research Foundation for the use of its facilities in Mammoth Cave National Park. This research was done in support of MACA-N-103.

\section{REFERENCES}

Altman P. L. and Dittmer D. S. (1968) Metabolism. Fedn Am. Soc. exp. Biol. Bethesda, Maryland.

Arlian L. G. and Veselica M. M. (1979) Water balance in insects and mites. Comp. Biochem. Physiol. 64A, 191-200.

Bedel L. and Simon S. (1875) Liste generale des Articules cavernicoles de l'Europe. Journal de Zoologie IV.

Bull E. and Mitchell R. W. (1972) Temperature and relative humidity responses of two Texas cave-adapted millipeds, Cambala speobia (Cambalidae: Cambalidae) and Speodesmus bicornourus (Polydesmida: Vanhoeffenüdae). Int. J. Speleol. 4, 365-393.

Campbell G. D. (1976) Activity rhythm in the cave cricket,
Ceuthophilus conicaudus Hubbell. Am. Midl. Nat. 96, 350-366.

Campbell G. D. (1980) Aspects of the ecology, environmental physiology and behaviour of several Australian cavc-dwelling crickets. Ph.D. Dissertation, University of New South Wales.

Edney E. B. (1971) Some aspects of water balance in tenebrionid beetles and a thysanuran from the Namib Desert of southern Africa. Physiol. Zool. 44, 61-76.

Edney E. B. (1977) Water Balance in Land Arthropods. Springer-Verlag, Berlin.

Edwards C. (1971) Relative humidity and temperature preference responses of the ricinuleid Cryptocellus pelaez (Arachnida). M.S. Thesis, Texas Tech. University.

Iladley N. F., Ahearn G. A. and Howarth F. G. (1981) Water and metabolic relations of cave-adapted and epigean lycosid spiders in Hawaii. J. Arachnol. 9, 215222.

Herreid C. F. II (1969) Water loss of crabs from different habitats. Comp. Biochem. Physiol. 28A, 829-839.

Holdgate M. W. (1956) Transpiration through the cuticles of some aquatic insects. $J$. exp. Biol. 33, 107-118.

Leja W. and Poulson T. L. (1984) Nocturnal cave exodus and return: cave vs camel crickets. Cave Research Foundation Annual Report, 1984, pp. 18-20.

Lucarelli M. and Sbordoni V. (1977) Humidity responses and the role of Hamann's organ of cavernicolous Bathysciinae (Coleoptera: Catopidae). Int. J. Speleol. 9, 167177.

Mead-Briggs A. R. (1956) The effect of temperature upon the permeability to water of arthropod cuticles. $J$. exp. Biol. 33, 737- 749 .

Mitchell R. W. (197I) Preference responses and tolerances of the troglobitic carabid beetle Rhadine subterranea. Int. J. Speleol. 3, 249-270.

Studier E. H., Lavoie K. H., Wares II W. D. and Linn J. A. M. (1986a) Bioenergetics of the cave cricket. Hadenoecus subterraneus. Comp. Biochem. Physiol. 84A, $431-436$

Studier E. H., Lavoie K. H., Wares II W. D. and Linn J. A. M. (1986b) Bioenergetics of the camel cricket, Ceuthophilus stygius. Comp. Biochem. Physiol. 86A, 91-95.

Vandel A. (1965) Biospeleology: The Biology of Cauernicolous Animals. International Series of Monographs in Pure and Applied Biology, Vol. 22, Pergamon Press, London.

Vannier G. (1977) Relations hydriques chez deux especes de Tomoceridae (Insectes Collemboles), peuplant des niveaux ecologiques separes. Bull. Soc. Zool. Fr. 102, 63 -79.

Wharton G. W. (1985) Water balance of insects. In Comprehensive Insect Physiology, Biochemistry and Pharmacology, (Edited by Kerkut G. A. and Gilbert L. I.). Vol. 4, pp. 565-601. Pergamon Press, Oxford.

Wigglesworth V. B. (1945) Transpiration through the cuticle of insects. J. exp. Biol. 21, 97-114.

Wilson J. (1975) The effect of low humidity on the distribution of Heteromurus nitidus (Collembola) in Radford Cave, Devon. Trans. Br. Cane Res. Assoc. 2, 123126.

Winston P. W. and Bates D. H. (1960) Saturated solutions for the control of humidity in biological research. Ecology 41, 232237 